\title{
Ameliorative effect of Amaranthus tricolor L. leaves on scopolamine-induced cognitive dysfunction and oxidative stress in rats
}

Vrushabh B. Hupparage ${ }^{1 *}$, Vijaykumar P. Rasal ${ }^{1}$, Vishal S. Patil ${ }^{1,2^{*}}$, Priyanka P. Patil ${ }^{1,2}$, Shubham G. Mulange ${ }^{1}$, Ajay P. Malgi ${ }^{1}$, Sathgowda A. Patil ${ }^{1}$, Ashwini R. Karade ${ }^{1}$

${ }^{1}$ Department of Pharmacology and Toxicology, College of Pharmacy, KLE Academy of Higher Education and Research, Belagavi, India.

${ }^{2}$ ICMR-National Institute of Traditional Medicine, Belagavi, India.

\begin{tabular}{l}
\hline ARTICLE INFO \\
\hline Received on: $02 / 06 / 2020$ \\
Accepted on: $24 / 08 / 2020$ \\
Available online: $05 / 10 / 2020$
\end{tabular}

\section{Key words:}

Cognitive dysfunction, Alzheimer's disease,

Amaranthus tricolor L., Scopolamine, Donepezil, Neuroprotective.

\begin{abstract}
Ayurveda is a holistic system that uses mostly herbs and minerals in prescriptions that play a crucial role in the treatment of various diseases because of their therapeutic effects, often on multiple targets. In the present study, we assessed the memory-enhancing activity of a leafy vegetable "Amaranthus tricolor L." against scopolamine (SCP)induced cognitive dysfunction and oxidative stress in rats. Initially, we screened A. tricolor leaves' ethanolic extract for its acetylcholinesterase $(\mathrm{AChE})$ inhibitory and antioxidant activity using standard procedures. The memory-enhancing activity in rats was performed by using the Morris water maze (MWM), the elevated plus maze (EPM), Actophotometer, and Cook's pole climbing (CPC) apparatus. Biochemical parameters, mainly $\mathrm{AChE}$ and butyrylcholinesterase (BChE) enzyme levels measured in the hippocampus and cortex, amyloid beta, reduced glutathione (GSH), superoxide dismutase, and lipid peroxidation (LPO) level, were measured in whole brain tissue. A. tricolor leaves' extract showed potent AChE inhibition and antioxidant activity on the scavenging of 2,2-diphenyl-1-picryl-hydrazyl-hydrate (DPPH). The EPM, MWM, CPC, and Actophotometer showed that SCP administration increased transfer latency (TL) and decreased escape latency time (ELT) and locomotion, respectively, on day 7 and 14, whereas combined therapy of SCP with Donepezil and SCP with $800 \mathrm{mg} / \mathrm{kg}$ A. tricolor extract significantly reversed the ELT, TL, and locomotion from day 7 to 14 . Moreover, $\mathrm{AChE}$ and BChE activities and GSH and Malondialdehyde (MDA) levels were significantly elevated in SCP-treated rats, and treatment with $A$. tricolor elevated the biochemical parameters altered by the SCP administration. A. tricolor L. leaves' extract ameliorates SCP-induced cognitive dysfunction and oxidative stress by the restoration of the cholinergic system's function, inhibiting Amyloid precursor protein (APP) deposition, and via antioxidant potency, i.e. increasing GSH level, by inhibiting the LPO in the brain. The current study suggests that $A$. tricolor L. leaves could be a valuable source for the treatment of cognitive dysfunction and oxidative stress associated with Alzheimer's disease.
\end{abstract}

\section{INTRODUCTION}

During the twentieth century, the significant increase in life expectancy made Alzheimer's disease (AD) the most widely perceived progressive neurodegenerative disorder (NDD) with high incidence and multifaceted pathogenesis. AD is a polygenic

\footnotetext{
"Corresponding Authors

Vrushabh B. Hupparage, Department of Pharmacology and Toxicology, College of Pharmacy, KLE Academy of Higher Education and Research, Belagavi,India.E-mail:vhupparage77@gmail.com

Vishal S. Patil, ICMR-National Institute of Traditional Medicine, Belagavi, India.E-mail: vishalpatil6377@gmail.com
}

disease that involves multi-protein and multi-pathways in its progression (Uddin et al., 2016). AD is characterized by the presence of extreme amounts of extracellular deposits containing insoluble amyloid- $\beta$ plaques, neurofibrillary tangles, and cholinergic deficits. The etiology of $\mathrm{AD}$ remains obscure because this disease is perplexingly caused by aging in concert with a complex interaction of both genetic factors and environmental risk. Numerous studies have reported that central cholinergic neurons are involved in learning and memory. During aging, the elevated central cholinergic system is associated with the decline in memory storage, ultimately impairing the retention of newly assimilated information (Huang et al., 2009). Hence, AD is an age-related progressive NDD that involves unavoidable loss of cognition, accounting for $\sim 60 \%$ of all cases, and over $35 \mathrm{M}$ people 
are diagnosed with $\mathrm{AD}$ worldwide and about 7.7M new cases are diagnosed every year (Ali et al., 2015).

Currently, there is no satisfactory treatment available for $\mathrm{AD}$. The current $\mathrm{AD}$ therapy includes utilization of conventional acetylcholinesterase $(\mathrm{AChE})$ inhibitors, viz. tacrine, physostigmine, and donepezil. However, extreme utilization of these agents is associated with negative effects (Asaduzzaman et al., 2014). In this way, it investigates the use of conventional spices as an elective resource for the treatment or management of various cognitive disorders. Herbal medicines are widely utilized as a major source for the treatment of cognitive dysfunctions due to the presence of various chemical constituents, antioxidant properties, and are associated with less toxicity compared to modern synthetic medicines. Furthermore, antioxidants have endogenous and exogenous properties which control the oxidation of neuron cells and act against oxidative stressrelated harmful effects. The major role of antioxidants is scavenging free radicals and improving the antioxidant status (Uttara et al., 2009). In order to regulate the development of free radical-mediated oxidative stress in the brain, antioxidant defense enzymes, such as reduced glutathione (GSH), catalase, and lipid peroxidation (LPO), play an important role (Sharma et al., 2013).

Amaranthus tricolor L. belongs to the family Amaranthaceae. A. tricolor is also known as "Tambdi Bhaji/Lal Saag" and is native to a large part of India. The leaves are rich in antioxidant compounds, act as a free radical scavengers (defense mechanism against oxidation), reduce oxidative stress, and act as an anti-inflammatory herb. The alkaloids, carbohydrates, cardiac glycosides, flavonoids, phenol, amino acids/proteins, saponins, tannins, terpenoids, pterocarpans, triterpenes, steroids, quinones, resins, and "coumarins" are found to be the major chemical constituents of the leaves. A. tricolor leaves were utilized as traditional medicine and for neuroprotection, as an astringent, to strengthen the liver and improve vision, as a hepatoprotective and anti-nociceptive, and as an anti-inflammatory, anti-cancer, and anti-arthritic (Al-Dosari et al., 2010; Amicarelli et al., 2012; Amornrit et al., 2016; Sable et al., 2017). Therefore, the present study aimed to evaluate the effect of $A$. tricolor leaves' ethanolic extract on scopolamine (SCP)-induced cognitive dysfunction and oxidative stress in rats.

\section{MATERIALS AND METHODS}

\section{Chemicals and equipment}

SCPHBr(Vital Laboratories Pvt. Ltd, Gujarat), Donepezil (Apotex pharmaceuticals, Bengaluru), Acetylthiocholine iodide (Sigma, St. Louis, MO), 5,5'-dithio-bis-(2-nitrobenzoic acid) (Sigma, St. Louis, MO), and distilled water were used wherever mentioned. Double distilled ethanol was used for extraction. Enzyme-linked immunosorbent assay (ELISA) plate reader (Thermo Scientific Multiskan GO version 1.00.40), centrifuge (Remi), elevated plus maze (EPM), Morris' water maze (MWM), Actophotometer (INCO, Ambala, India), Cook's pole climbing (CPC) apparatus (INCO), electronic weighing balance, rotary evaporator, refrigerator, etc. were used in the current study.

\section{Plant material}

Amaranthus tricolor fresh leaves were collected from Dhamane (15.797209, 74.545502), Belagavi, Karnataka, India.
The plant leaves were authenticated by Dr. Harsha Hegde, Scientist E, ICMR-National Institute of Traditional Medicine, Belagavi. Accession number: RMRC-1440. The herbarium was prepared and stored for further reference. The fresh leaves were washed under distilled water to remove adhered dirty material, shade dried, coarsely powdered, and subjected to maceration using 95\% $v / v$ ethanol for 7 days with occasional shaking. After maceration, the powder obtained was further subjected to Soxhlet extraction. The mixture was filtered and concentrated using a rotary evaporator under reduced pressure. The extract was stored in an airtight light resistance glass container for further use.

\section{In vitro antioxidant assay}

\section{DPPH radical scavenging assay}

The DPPH radical scavenging assay was analyzed by using the Blois method (Blois et al., 1958). A stock solution of $1 \mathrm{mg} / \mathrm{ml}$ plant extract, $1 \mathrm{mg} / \mathrm{ml}$ Ascorbic acid, $5.85 \mathrm{mg}$ DPPH in $150 \mathrm{ml}$ methanol was prepared and stored in the light resistance area. Briefly, $0.4 \mathrm{ml}$ plant extract $(50-800 \mu \mathrm{g} / \mathrm{ml})$ and the standard drug were mixed with a $3.6 \mathrm{ml}$ methanolic solution of DPPH $(0.1$ $\mathrm{mM})$. An equal amount of methanol $(0.4 \mathrm{ml})$ was used as a blank with a DPPH solution $(3.6 \mathrm{ml})$. The above-mentioned mixture was vortexed for 1 minute and incubated for 30 minutes at $37^{\circ} \mathrm{C}$. After incubation, the absorbance of each sample against methanol as blank by using the ELISA microplate reader at $517 \mathrm{~nm}$ was noted. The percentage of DPPH scavenging was calculated by using the following formula: DPPH inhibition $(\%)=\left(A_{\text {control }}-A_{\text {sample }} / A_{\text {control }}\right) \times$ 100. The results were reported as $\mathrm{IC}_{50}$ value.

\section{In vitro $\mathrm{AChE}$ enzyme assay}

AChE enzyme inhibition activity was performed according to Ellman's method (Ellman et al., 1961). The AChE enzyme of $6.67 \mathrm{U} / \mathrm{ml}^{-1}$ stock solution was prepared by dissolving it in $20 \mathrm{mM}$ sodium Phosphate-buffered saline (PBS) (pH 7.6), and the solutions were stored at $-80^{\circ} \mathrm{C}$ for further use. Acetylthiocholine iodide was used as a substrate. In a test tube, $1.7 \mathrm{ml}$ of $50 \mathrm{mM}$ Tris $\mathrm{HCl}$ buffer $(\mathrm{pH} 8.0)$ and $250 \mu \mathrm{l}$ of different concentrations of plant extract $(10,20,40,80,160$, and $320 \mu \mathrm{g} / \mathrm{ml})$ and donepezil (1, 2, $4,8,16$, and $32 \mu \mathrm{g} / \mathrm{ml}$ ) were added. To the above mixture, $10 \mu \mathrm{l}$ AChE enzyme and $20 \mu \mathrm{l}$ DTNB were added. The mixture was incubated for 15 minutes and $10 \mu 1$ acetylthiocholine iodide was added; immediately, the absorbance was read at $412 \mathrm{~nm}$ for every 45 seconds for 3 minutes. The enzyme inhibition was calculated from the rate of change in absorbance with time.

$$
\begin{aligned}
\% \text { Inhibition }= & 100-(\text { Change of sample Abs } / \\
& \text { Change of blank Abs }) \times 100
\end{aligned}
$$

\section{Experimental animals}

Wistar rats (either sex, $180 \pm 20 \mathrm{~g}$ ) were acquired from Invivo Biosciences, Bengaluru, housed in a clean and transparent polypropylene cage, and were divided into six groups $(n=6)$. Animals were maintained under the 12 hours light-dark cycle at $23^{\circ} \mathrm{C} \pm 2{ }^{\circ} \mathrm{C}$. Relative humidity was maintained at $45 \%-55 \%$. The study protocol was reviewed and approved by the Institutional Animal Ethical Committee, KLE College of Pharmacy, Belagavi, Resolution No. KLECOP/CPCSEA - Reg.No.221/Po/Re/S/2000/ 
CPCSEA, Res.28-12/10/2019. The animal experiments were carried out as per CPCSEA guidelines.

\section{Experimental procedure}

The dose of the extract was selected based on the previously reported acute toxicity study reports. Ethanolic extract of leaves showed no mortality at $2,000 \mathrm{mg} / \mathrm{kg}$, thus we selected the $1 / 2.5$ th, $1 / 5$ th, $1 / 10$ th doses of the $\mathrm{LD}_{50}$ value as therapeutic doses. The extract was administered orally using Carboxymethyl cellulose (CMC) as a suspending agent (Al-Dosari et al., 2010). Group I received food and water. Group II (negative control) received SCP (1 mg/kg/day i.p.) for 14 days (Zahra et al., 2015). Group III (positive control) received SCP (1 mg/kg/day; i.p.) with donepezil $\mathrm{HCl}(3 \mathrm{mg} / \mathrm{kg} /$ day; p.o.) for 14 days (Zahra et al., 2015). Group IV, V, and VI received SCP (1 mg/kg/day; i.p.) with $A$. tricolor L. extract of 200, 400, and $800 \mathrm{mg} / \mathrm{kg} / \mathrm{day}$, p.o., respectively, for 14 days. All the animals were subjected to exteroceptive behavioral models of memory on day 0,7 , and 14 , and brain tissue samples for biochemical estimation.

\section{In vivo screening models for memory (exteroceptive behavioral models)}

\section{Elevated plus maze}

Short-term memory was evaluated by using Bhuvanendran et al.'s (2018) method. The EPM consists of two open arms crossed over two closed arms having dimensions of 50 $\times 10 \mathrm{~cm}$. Four arms were connected using a central square having $10 \times 10 \mathrm{~cm}$ dimensions. During the assessment of memory via the EPM, the rats were individually placed at one end of the open arm facing away from the central stage (platform), and the time taken for the rat to move from an open arm to a closed arm (initial transfer latency) was recorded using a stopwatch. The animals were allowed to explore the maze for 120 seconds. If the animal did not enter the closed arms within 120 seconds, it was directed on the back into one of the closed arms and the transfer latency (TL) was given as 120 seconds. Later, the rat was allowed to explore the maze for 30 seconds to become familiar with the maze and was then returned to its cage. Each group was tested on day 0,7 , and 14.

\section{Morris water maze}

Escape latency time (ELT) was assessed using Ishola et al.'s (2018) method. It consists of a large circular water tank having $110 \mathrm{~cm}$ diameter and $60 \mathrm{~cm}$ height. It is made of black opaque polyvinyl chloride or hardboard coated with fiberglass or resin with a white surface and filled with water $\left(26^{\circ} \mathrm{C} \pm 2{ }^{\circ} \mathrm{C}\right)$ to a depth of $30 \mathrm{~cm}$. The floor of the circular tank was marked into four equal quadrants. In all trials, $2 \mathrm{~cm}$ below the surface of the water, a black round platform of $10 \mathrm{~cm}$ diameter was placed in a constant position. The cut-off time given to individual rats was 120 seconds. The time taken for the rat to locate the escape platform was noted. If the rat was unable to find/locate the platform within the cut-off time, it was directed to the stage (platform) and was permitted to stay on it for 10 seconds. Each group was tested on day 0, 7, and 14.

\section{Actophotometer}

Photoactometer is utilized to access locomotion in the experimental animals. The apparatus functions based on photoelectric cells that are connected to the circuit with a counter. A motion count was recorded when the beam of light falling on the photocell was cut off by the rat. The cut-off time given to individual rats was 120 seconds. Each rat's locomotor activity was noted. Each time the apparatus was wiped with $10 \%$ ethanol to avoid intervention due to animal odor. Each group was tested on day 0, 7, and 14 (Bhosale et al., 2011).

\section{Cook's pole climbing}

Cook's pole climbing method is a conditional avoidance/ escape latency procedure used to screen Central nervous system (CNS) activity. The apparatus' floor acts as a source of shock. The experimental rats were subjected to training under a well-closed, electrical, grid-less, light chamber with a buzzer. This was carried routinely. Animals were subjected to training in such a way that the animal learned to climb the pole within 120 seconds. Each group was tested on day 0, 7, and 14 (Kadian et al., 2014).

\section{Biochemical estimation}

Cerebral cortex and hippocampus AChE and Butyrylcholinesterase (BChE) enzymes estimation

At the end of the study, the rats are decapitated; their brains are removed quickly and kept in ice-cold saline. The cerebral cortex and hippocampus were isolated, weighed, and homogenized in $0.1 \mathrm{M}(\mathrm{pH}$ 8) PBS. Briefly, $0.4 \mathrm{ml}$ of the homogenate was added to a test tube containing $2.6 \mathrm{ml}$ PBS $(0.1 \mathrm{M}, \mathrm{pH} 8)$. Furthermore, $100 \mu \mathrm{l}$ of DTNB reagent, followed by $t 20 \mu \mathrm{l}$ of acetylthiocholine iodide solution (butyrylthiocholine iodide for BChE enzyme estimation), was added. The absorbance was then noted at $412 \mathrm{~nm}$ for 5 minutes and change in absorbance per minute was also noted (Ellman et al., 1961). The "rate of moles of substrate hydrolyzed per minute per gram of tissue" was calculated by the following equation: $R=5.74 \times 10^{-4}(\Delta \mathrm{A} / \mathrm{Co})$. Where $R=$ rate in moles of substrate hydrolyzed per minute per gram of tissue; $\Delta \mathrm{A}=$ change in absorbance per minute; and $\mathrm{Co}=$ original concentration of tissue $(\mathrm{mg} / \mathrm{ml})$.

\section{Estimation of amyloid beta $\left(A \beta_{1-42}\right)$}

The capacity of rat brain $A \beta_{1-42}$ levels was estimated according to the sandwich ELISA kit for rat $A \beta_{1-42}$ manual ( $\mathrm{YH}$ Bioresearch Laboratory, Shanghai, China) (Pattanashatti et al., 2017). The weighed brain tissue sample was homogenized in $0.1 \mathrm{M}$ PBS (pH 7.4) and centrifuged at 5,000 rpm. The supernatant was used for the detection of $A \beta_{1-42}$. All reagents, standard solutions, and samples were prepared as per instructions and methodology given in the manual. Reagents were kept at room temperature before use (assay solutions should be at room temperature). The standard curve analysis was run in parallel to the test samples. The absorbance was measured in the multi-scan spectrum spectrophotometer (Thermo Scientific, Waltham, MA, Multiskan $\mathrm{GO})$ at $450 \mathrm{~nm}$. All the readings were performed in triplicate.

\section{In vivo antioxidants}

Rat brain was removed, weighed, and homogenized in cold $0.05 \mathrm{M}$ PBS ( $\mathrm{pH} 7.4$ ). Furthermore, homogenates were centrifuged at $10,000 \mathrm{rpm}$ for 10 minutes at $4^{\circ} \mathrm{C}$ (MPW-350 R, Korea) and post-mitochondrial supernatant was utilized for the 
estimation of Total protein (TP) and LPO. The supernatant was further centrifuged at $15,000 \mathrm{rpm}$ for 1 hour at $4^{\circ} \mathrm{C}$. The supernatant obtained was utilized to estimate superoxide dismutase (SOD) and GSH (Shalavadi et al., 2012).

\section{Estimation of LPO in rat brain}

Thiobarbituric acid reactive substances in the homogenate were estimated by the method described by Shalavadi et al. (2012). Briefly, $0.5 \mathrm{ml}$ of $10 \%$ homogenate was incubated with $15 \%$ Trichloroacetic acid (TCA), 0.375\% 2-Thiobarbituric acid (TBA), and $5 \mathrm{~N} \mathrm{HCl}$ at $95^{\circ} \mathrm{C}$ for 15 minutes; the mixture was cooled, centrifuged, and the absorbance of the supernatant was measured at $512 \mathrm{~nm}$ against an appropriate blank. The LPO levels were determined by using the following equation: $\varepsilon=1.56 \times 105 \mathrm{M}^{-1} \mathrm{~cm}^{-1}$.

\section{Estimation of reduced GSH}

$5 \%$ tissue homogenate was prepared in $20 \mathrm{mM}$ Ethylenediaminetetraacetic acid (EDTA) ( $\mathrm{pH}$ 4.7). Briefly, $100 \mu \mathrm{l}$ of the homogenate was added to $1 \mathrm{ml} 0.2 \mathrm{M}$ Tris-EDTA

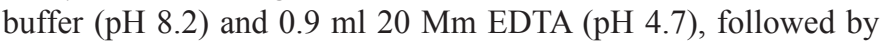
$20 \mu \mathrm{l}$ of Ellman's reagent (10 mmol/1 DTNB in methanol), and incubated for 30 minutes. Samples were further centrifuged and the absorbance was noted at $412 \mathrm{~nm}$.

\section{Estimation of SOD}

SOD activity was estimated based on the ability of SOD to inhibit the auto-oxidation of epinephrine to adrenochrome at alkaline $\mathrm{pH}$. Briefly, $25 \mu \mathrm{l}$ of the supernatant obtained from the centrifuged brain homogenate was added to a mixture of 0.1 $\mathrm{mM}$ epinephrine in carbonate buffer $(\mathrm{pH}$ 10.2). The formation of adrenochrome was measured at $295 \mathrm{~nm}$. The SOD activity (U/mg of protein) was calculated by using the standard plot.

\section{Statistical analysis}

The results were expressed as Mean \pm SEM. The difference among the group was determined using one-way and two-way analyses of variance (ANOVA), followed by Tukey's multiple comparison test and Bonferroni's multi-comparison test as post hoc tests using GraphPad Prism software version 5.0.

\section{RESULTS}

\section{Plant extraction}

The percentage yield $(w / w)$ of $A$. tricolor L. leaves' ethanolic extract by maceration method was found to be $5.2 \%$, followed by the Soxhlet extraction method, which was found to be $2.3 \%$.

\section{In vitro antioxidant assay}

\section{$D P P H$ radical scavenging assay}

Ascorbic acid was used as the reference compound. The $\mathrm{IC}_{50}$ value of ascorbic acid was found to be $67.12 \mu \mathrm{g} / \mathrm{ml}$, whereas $\mathrm{IC}_{50}$ value of $A$. tricolor extract was found to be $236.42 \mu \mathrm{g} / \mathrm{ml}$. The results suggest that the ascorbic acid has a more radical scavenging activity compared to the $A$. tricolor ethanolic extract. The $\mathrm{IC}_{50}$ value is shown in Figure 1a and Table 1.

\section{b) In vitro Acetylcholinesterase Enzyme Assay}

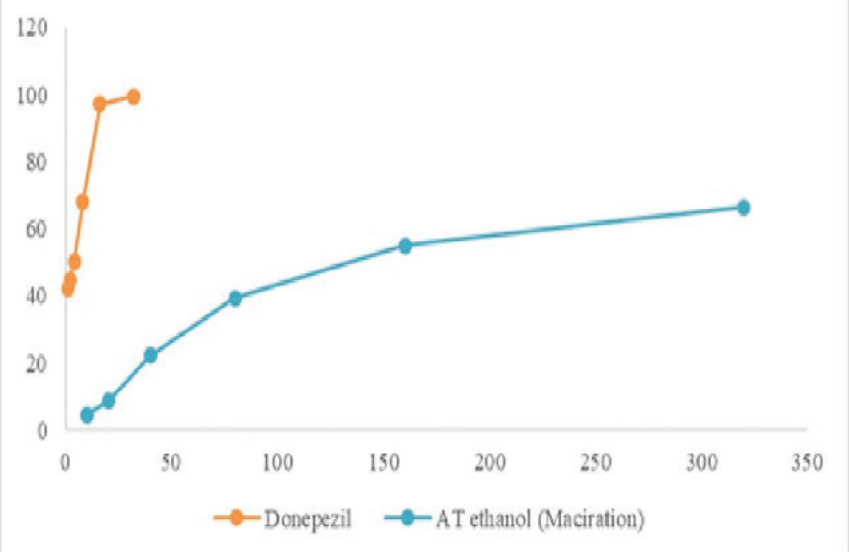

Figure 1. The effect of A. tricolor leaves' extract on (a) DPPH radical scavenging and (b) AChE enzyme.

Table 1. Effect of A. tricolor on free radical scavenging assay by using DPPH and AChE enzyme.

\begin{tabular}{|c|c|c|c|c|}
\hline \multirow{2}{*}{ Test agent } & \multicolumn{2}{|c|}{ DPPH radical scavenging assay } & \multicolumn{2}{|c|}{ AChE enzyme assay } \\
\hline & $y=m x+C$ & $\mathrm{IC}_{50}(\mu \mathrm{g} / \mathrm{ml})$ & $y=m x+C$ & $\mathrm{IC}_{50}(\mu \mathrm{g} / \mathrm{ml})$ \\
\hline Ascorbic acid & $y=0.0542 x+46.362 R^{2}=0.773$ & 67.12177 & - & - \\
\hline A. tricolor & $y=0.0649 x+34.656 R^{2}=0.7847$ & 236.4253 & $y=0.1943 x+12.325 R^{2}=0.8461$ & 193.9011837 \\
\hline Donepezil & - & - & $y=1.9808 x+46.102 R^{2}=0.8238$ & 1.967891761 \\
\hline
\end{tabular}




\section{In vitro AChE enzyme assay}

The AChE enzyme inhibitory activity of $A$. tricolor extract and clinically proven drug donepezil are shown in Table 1. The $\mathrm{IC}_{50}$ value of $A$. tricolor was found to be $193.9 \mu \mathrm{g} / \mathrm{ml}$ and donepezil was found to be $1.96 \mu \mathrm{g} / \mathrm{ml}$. This suggests that donepezil is 100 times more potent than $A$. tricolor extract. The $\mathrm{IC}_{50}$ value and standard calibration curve are shown in Figure $1 \mathrm{~b}$ and Table 1, respectively.

\section{In vivo studies}

\section{Effect of $A$. tricolor extract on TL using EPM}

The rats were exposed to the EPM to assess the TL retrieval of memory. The TL of the SCP group was significantly decreased on day $7(p<0.05)$ and $14(p<0.001)$ compared to the normal group, whereas SCP with Donepezil $3 \mathrm{mg} / \mathrm{kg}$ was significantly increased in TL on day $7(p<0.01)$ and $14(p<0.001)$ compared to SCP alone (Group II). However, the administration of SCP with Amaranthus tricolor L. (AT) $400 \mathrm{mg} / \mathrm{kg}$ and SCP + AT $800 \mathrm{mg} / \mathrm{kg}$ was significantly increased TL on day $14(p<0.01$ and $p<0.001$, respectively) compared with SCP alone (Group II). The effect of $A$. tricolor on TL is shown in Figure $2 \mathrm{a}$ and Table $2 \mathrm{a}$.

\section{Effect of $A$. tricolor extract on ELT using $M W M$}

The ELT was evaluated on day 0,7 , and 14 from the duration of the treatment period. Group II (SCP $1 \mathrm{mg} / \mathrm{kg} /$ day) showed significantly increased ELT on day 7 and 14 compared to the normal group $(p<0.001)$, whereas treatment of SCP with Donepezil $3 \mathrm{mg} / \mathrm{kg}$ significantly decreased ELT on day 7 and 14 $(p<0.001)$ compared to SCP alone. However, SCP with AT 200, 400 , and $800 \mathrm{mg} / \mathrm{kg}$ /day showed a significant decrease in ELT on day 7 and $14(p<0.001)$ compared to SCP alone. The effect of $A$. tricolor on ELT is shown in Figure $2 \mathrm{~b}$ and Table $2 \mathrm{~b}$.

\section{Effect of A. tricolor extract on locomotor activity using Actophotometer}

The locomotion of the SCP group was significantly decreased on day 7 and 14 ( $p<0.001)$ compared to the normal group. Treatment of SCP with Donepezil $3 \mathrm{mg} / \mathrm{kg}$ and SCP with AT 400 and $800 \mathrm{mg} / \mathrm{kg}$ group was significant increased $(p<0.001)$ on

\section{a) Elevated Plus Maze}

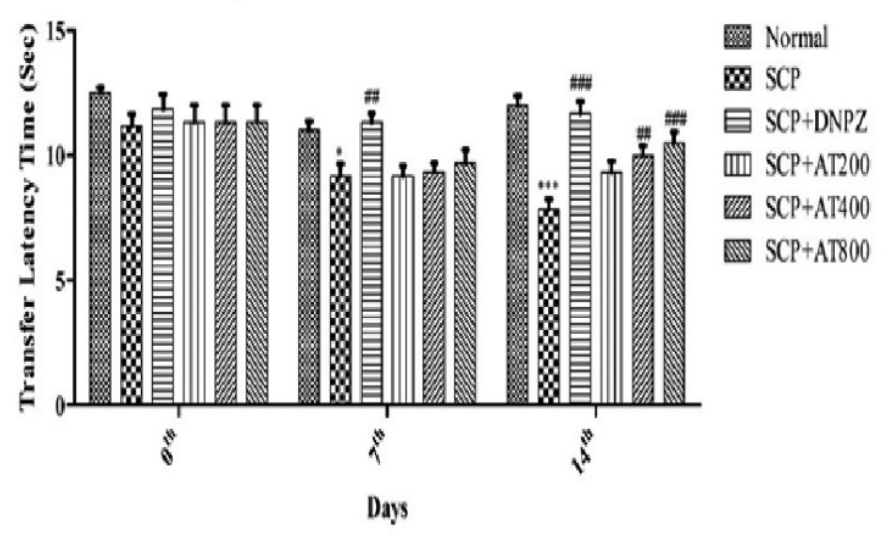

c) Actophotometer

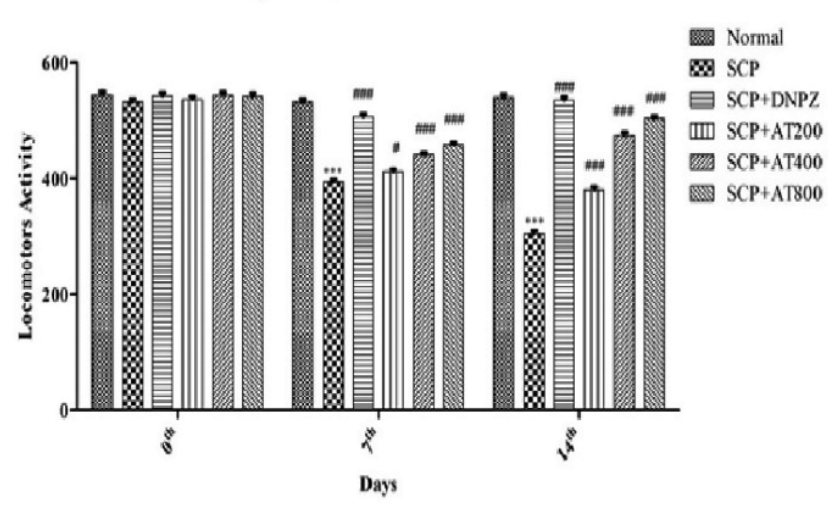

b) Morries Water Maze

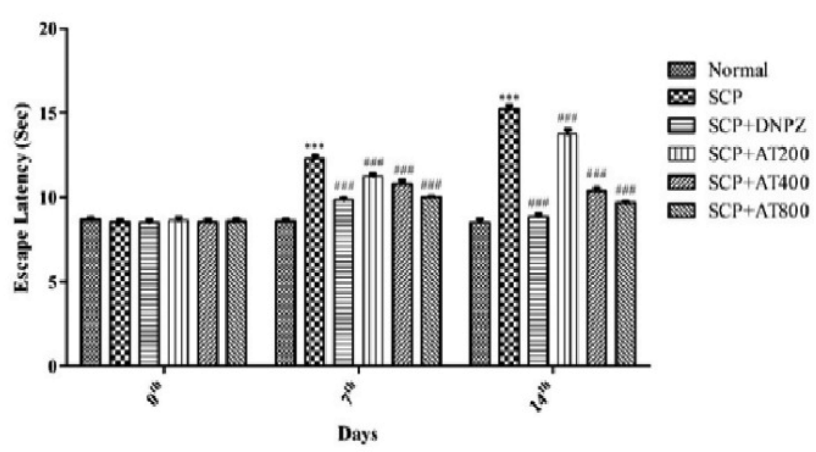

d) Cook's Pole Climbing

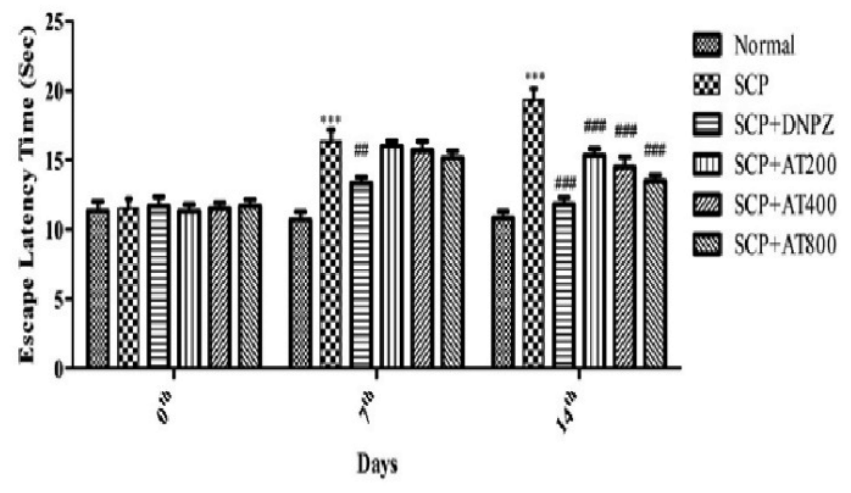

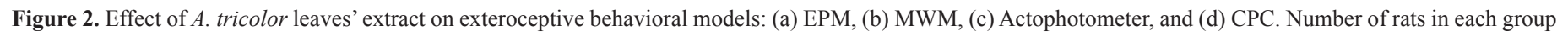

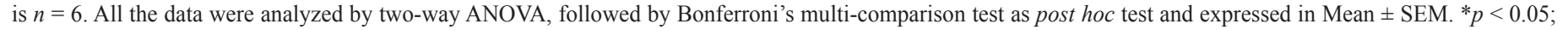

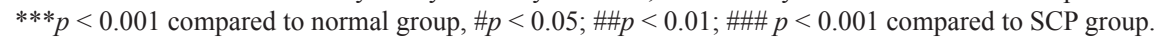


Table 2a. Effect of A. tricolor on TL using EPM.

\begin{tabular}{lccc}
\hline \multirow{2}{*}{ Treatment groups } & \multicolumn{3}{c}{ TL } \\
\cline { 2 - 4 } & 0th day & 7th day & 14th day \\
\hline Normal & $12.50 \pm 0.224$ & $11.00 \pm 0.365$ & $12.00 \pm 0.365$ \\
SCP & $11.16 \pm 0.477$ & $09.16 \pm 0.477^{*}$ & $07.83 \pm 0.401^{\text {**** }}$ \\
SCP+DNPZ & $11.83 \pm 0.601$ & $11.33 \pm 0.333^{\ldots \#}$ & $11.66 \pm 0.494^{\ldots \ldots}$ \\
SCP+AT200 & $11.33 \pm 0.667$ & $09.16 \pm 0.401$ & $09.33 \pm 0.422$ \\
SCP+AT400 & $11.33 \pm 0.667$ & $09.33 \pm 0.333$ & $10.00 \pm 0.365^{\ldots \#}$ \\
SCP+AT800 & $11.33 \pm 0.667$ & $09.67 \pm 0.558$ & $10.50 \pm 0.428^{\ldots \ldots \ldots}$ \\
\hline
\end{tabular}

Values are expressed in mean \pm SEM; $(n=6)$; Analyzed by two-way ANOVA, followed by Bonferroni's multi-comparison test as post hoc test.

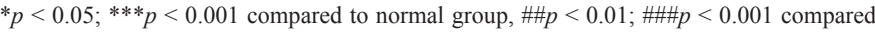
to $\mathrm{SCP}$ group.

Table 2b. Effect of $A$. tricolor on ELT using MWM.

\begin{tabular}{|c|c|c|c|}
\hline \multirow{2}{*}{ Treatment groups } & \multicolumn{3}{|c|}{ ELT } \\
\hline & 0th day & 7th day & 14th day \\
\hline Normal & $08.66 \pm 0.124$ & $08.58 \pm 0.124$ & $08.50 \pm 0.214$ \\
\hline SCP & $08.54 \pm 0.119$ & $12.29 \pm 0.176^{* * *}$ & $15.20 \pm 0.218^{* * *}$ \\
\hline $\mathrm{SCP}+\mathrm{DNPZ}$ & $08.50 \pm 0.171$ & $09.83 \pm 0.124^{\# \# \#}$ & $08.83 \pm 0.167$ \\
\hline $\mathrm{SCP}+\mathrm{AT} 200$ & $08.62 \pm 0.168$ & $11.25 \pm 0.129^{\# \#}$ & $13.75 \pm 0.266^{\ldots \ldots}$ \\
\hline $\mathrm{SCP}+\mathrm{AT} 400$ & $08.54 \pm 0.164$ & $10.79 \pm 0.198^{\# \# \#}$ & $10.37 \pm 0.180^{\# \#}$ \\
\hline $\mathrm{SCP}+\mathrm{AT} 800$ & $08.58 \pm 0.139$ & 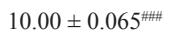 & $09.66 \pm 0.053^{\ldots \#}$ \\
\hline
\end{tabular}

Values are expressed in mean $\pm \operatorname{SEM} ;(n=6)$; Analyzed by two-way ANOVA, followed by Bonferroni's multi-comparison test as post hoc test.

*** $p<0.001$ compared to normal group, \#\# $<<0.001$ compared to SCP group.

Table 2c. Effect of A. tricolor on locomotion using Actophotometer.

\begin{tabular}{|c|c|c|c|}
\hline \multirow{2}{*}{ Treatment groups } & \multicolumn{3}{|c|}{ Locomotor Activity } \\
\hline & 0th day & 7th day & 14th day \\
\hline Normal & $544.33 \pm 5.608$ & $531.83 \pm 5.023$ & $539.50 \pm 5.476$ \\
\hline SCP & $531.83 \pm 5.023$ & $393.00 \pm 4.789^{* * *}$ & $303.83 \pm 5.394^{* * * *}$ \\
\hline $\mathrm{SCP}+\mathrm{DNPZ}$ & $542.00 \pm 5.317$ & $506.00 \pm 5.317^{\# \# \#}$ & $534.83 \pm 5.689$ \\
\hline $\mathrm{SCP}+\mathrm{AT} 200$ & $536.16 \pm 5.102$ & $411.16 \pm 4.534^{\#}$ & $379.83 \pm 5.570^{\ldots \ldots \ldots}$ \\
\hline $\mathrm{SCP}+\mathrm{AT} 400$ & $543.66 \pm 5.232$ & $440.83 \pm 4.061^{\# \#}$ & $473.16 \pm 5.357^{\# \ldots \#}$ \\
\hline $\mathrm{SCP}+\mathrm{AT} 800$ & $541.66 \pm 5.136$ & $458.00 \pm 3.759^{\# \# \#}$ & $503.16 \pm 4.110^{\ldots \# \#}$ \\
\hline
\end{tabular}

Values are expressed in mean $\pm \operatorname{SEM} ;(n=6)$; Analyzed by two-way ANOVA, followed by Bonferroni's multi-comparison test as post hoc test.

${ }^{* * *} p<0.001$ compared to normal group, $\# p<0.05$; \#\#\#p<0.001 compared to SCP group.

Table 2d. Effect of A. tricolor on ELT using CPC.

\begin{tabular}{lccc}
\hline \multirow{2}{*}{ Treatment groups } & \multicolumn{3}{c}{ ELT } \\
\cline { 2 - 4 } & 0th day & 7th day & 14th day \\
\hline Normal & $11.33 \pm 0.667$ & $10.66 \pm 0.615$ & $10.83 \pm 0.477$ \\
SCP & $11.50 \pm 0.719$ & $16.33 \pm 0.843^{* * * *}$ & $19.33 \pm 0.803^{* \text { *** }}$ \\
SCP + DNPZ & $11.66 \pm 0.667$ & $13.33 \pm 0.422^{\# \#}$ & $11.83 \pm 0.477^{\ldots \ldots \ldots}$ \\
SCP + AT200 & $11.33 \pm 0.494$ & $16.00 \pm 0.365$ & $15.33 \pm 0.494^{\ldots \ldots \ldots}$ \\
SCP + AT400 & $11.50 \pm 0.428$ & $15.66 \pm 0.667$ & $14.50 \pm 70.719^{\ldots \ldots \ldots}$ \\
SCP + AT800 & $11.66 \pm 0.494$ & $15.16 \pm 0.477$ & $13.50 \pm 0.428^{\ldots \ldots \ldots}$ \\
\hline
\end{tabular}

Values are expressed in mean \pm SEM; $(n=6)$; Analyzed by two-way ANOVA, followed by Bonferroni's multi-comparison test as post hoc test.

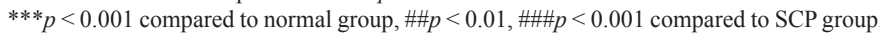

day 7 and day 14 and SCP with AT $200 \mathrm{mg} / \mathrm{kg}$ showed increased locomotion on day $14(p<0.001)$ compared to SCP group. The effect of A. tricolor on locomotion is shown in Figure 2c and Table 2c.

\section{Effect of A. tricolor extract on ELT using CPC apparatus}

The ELT was evaluated on day 0,7 , and 14 of treatment using CPC apparatus. SCP $1 \mathrm{mg} / \mathrm{kg} /$ day group showed a significant increase $(p<0.001)$ in ELT on day 7 and 14 compared to the normal group. Treatment of SCP with Donepezil $3 \mathrm{mg} / \mathrm{kg}$ showed a significant decrease in ELT on day $7(p<0.01)$ and $14(p<$ 0.001 ) compared to SCP alone. However, treatment of AT 200, 400 , and $800 \mathrm{mg} / \mathrm{kg}$ showed a significant reduction in ELT on day $14(p<0.001)$ compared to SCP alone. The effect of A. tricolor on ELT is shown in Figure 2d and Table 2d.

\section{In vivo biochemical studies}

\section{Effect of A. tricolor extract on AChE and BChE levels in rat hippocampus and cerebral cortex}

The SCP group showed a significant increase in AChE enzyme activity compared to the normal group $(p<0.001)$ in the hippocampus and cerebral cortex. Treatment of SCP with Donepezil (DNPZ) showed significantly reduced levels of AChE activity in the hippocampus and cortex $(p<0.001)$. However, no significant change in AChE activity was observed in the hippocampus and cortex on the treatment of SCP with AT $200 \mathrm{mg} / \mathrm{kg}$, whereas the treatment of SCP with AT $400 \mathrm{mg} / \mathrm{kg}$ showed significantly reduced AChE activity in the cortex $(p<0.01)$. Treatment of SCP with $800 \mathrm{mg} / \mathrm{kg}$ showed a significant change in AChE activity in the hippocampus $(p<0.05)$ and cortex $(p<0.001)$. The effect of $A$. tricolor on the hippocampus and cerebral cortex AChE enzyme activity is shown in Table 3 and Figure $3 a$ and $b$.

The SCP group showed a significant decrease in $\mathrm{BChE}$ enzyme activity compared to the normal group $(p<0.001)$ in the hippocampus and cerebral cortex. However, a significant increase in $\mathrm{BChE}$ activity was observed in the rat hippocampus and cortex treated of SCP with DNPZ $(p<0.01)$ compared to the SCP group. BChE enzyme activity is shown in Table 3 and Figure $3 \mathrm{c}$ and $\mathrm{d}$.

\section{Effect of A. tricolor extract on Amyloid-beta (1-42) level in rat whole brain}

The SCP group showed a significant increase in the level of Amyloid-beta $(1-42)$ compared to the normal $\operatorname{group}(p<0.001)$ in the whole rat brain. However, the treatment of SCP with Donepezil showed a significant decrease in Amyloid beta (1-42) in the whole brain $(p<0.001)$ compared to SCP alone. However, the treatment of SCP with AT $400 \mathrm{mg} / \mathrm{kg}$ showed a significantly reduced level of Amyloid-beta $(1-42)(p<0.01)$ and SCP with AT $800 \mathrm{mg} / \mathrm{kg}(p<$ $0.001)$ compared to SCP alone. The effect of $A$. tricolor on rat brain Amyloid beta (1-42) level is shown in Table 4 and Figure 4a.

\section{In vivo antioxidants}

\section{Effect of A. tricolor extract on MDA level in the brain}

The SCP group showed a significantly increased level of MDA $(p<0.001)$ compared to the normal group. Treatment of SCP with DNPZ showed a significant decline in the MDA level $(p$ 
Table 3. Effect of A. tricolor on the hippocampus and cerebral cortex AChE and BChE enzymes.

\begin{tabular}{|c|c|c|c|c|}
\hline \multirow{2}{*}{ Treatment groups } & \multicolumn{2}{|c|}{ AChE enzyme activity (in moles $\times 10^{-6} /$ minutes/g of tissue) } & \multicolumn{2}{|c|}{ BChE enzyme activity (in moles $\times 10^{-6} /$ minutes $/ g$ of tissue) } \\
\hline & Hippocampus & Cerebral cortex & Hippocampus & Cerebral cortex \\
\hline Normal & $06.06 \pm 0.251$ & $01.55 \pm 0.356$ & $11.10 \pm 0.321$ & $08.97 \pm 1.332$ \\
\hline $\mathrm{SCP}$ & $13.77 \pm 0.688^{* * *}$ & $10.83 \pm 0.240^{* * * *}$ & $04.38 \pm 0.656^{* * *}$ & $01.91 \pm 0.141^{* * * *}$ \\
\hline $\mathrm{SCP}+\mathrm{DNPZ}$ & $06.29 \pm 1.297^{\ldots \# \#}$ & $03.38 \pm 0.85^{\ldots \# \#}$ & $10.02 \pm 1.746^{\# \#}$ & $07.10 \pm 0.325^{\# \#}$ \\
\hline $\mathrm{SCP}+\mathrm{AT} 200$ & $12.63 \pm 0.664$ & $08.72 \pm 0.077$ & $05.13 \pm 0.242$ & $02.70 \pm 0.293$ \\
\hline $\mathrm{SCP}+\mathrm{AT} 400$ & $10.14 \pm 1.141$ & $06.82 \pm 0.147^{\# \#}$ & $06.32 \pm 0.455$ & $03.31 \pm 0.797$ \\
\hline $\mathrm{SCP}+\mathrm{AT} 800$ & $08.98 \pm 0.710^{\#}$ & $05.08 \pm 0.733^{\# \#}$ & $07.72 \pm 0.313$ & $03.57 \pm 0.211$ \\
\hline
\end{tabular}

Values are expressed in mean \pm SEM: $(n=6)$; Analyzed by one-way ANOVA, followed by Tukey's multiple comparison test.

*** $p<0.001$ compared to normal group, \#p<0.05; \# $p<0.01$;\#\# $p<0.001$ compared to SCP group.

a) AChE Activity in Hippocampus

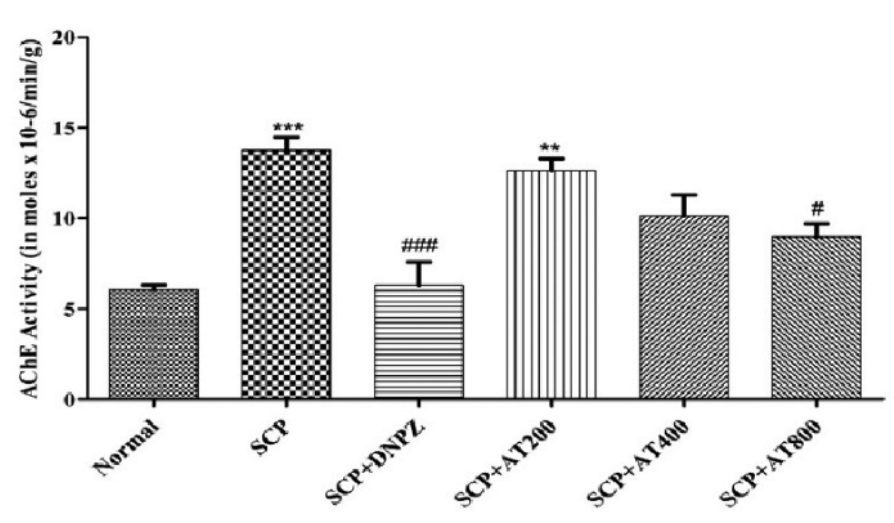

c) BChE Activity in Hippocampus

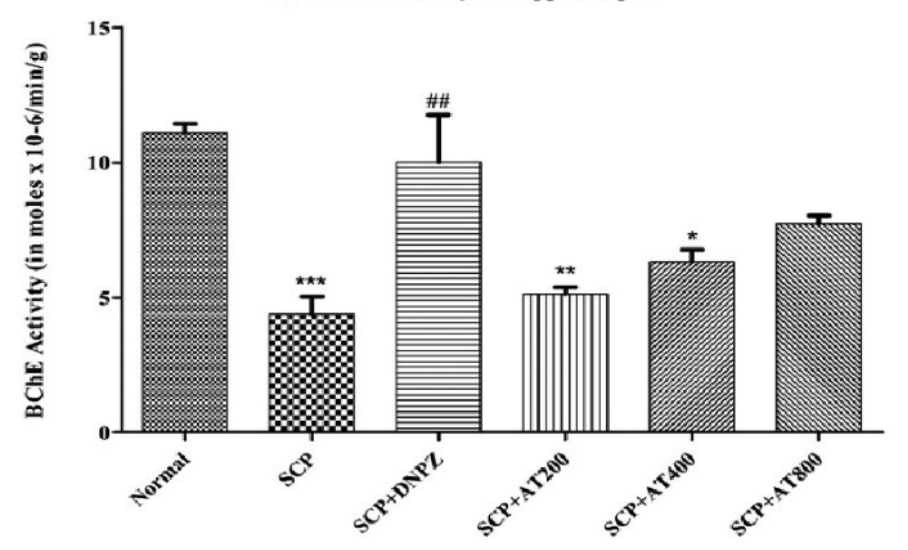

b) AChE Activity in Cortex

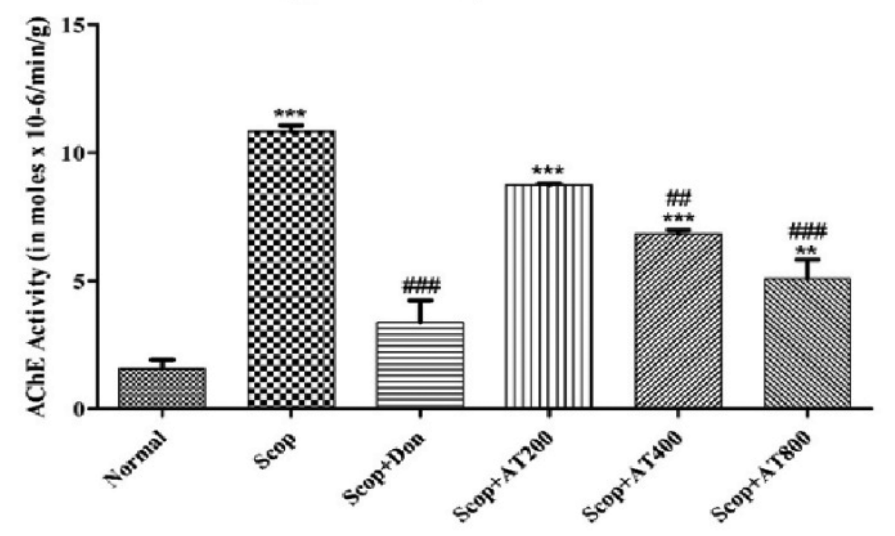

d) BChE Activity in Cortex

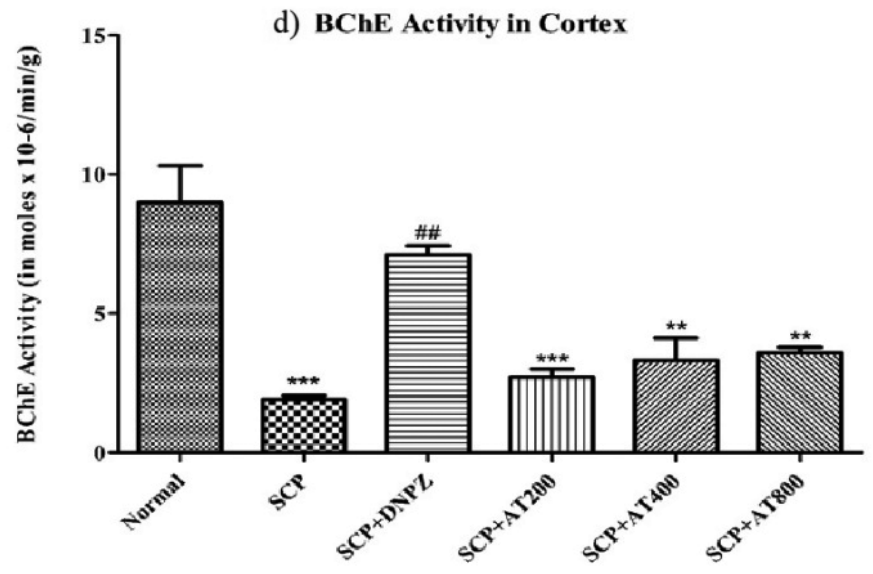

Figure 3. Effect of A. tricolor leaves; extract on hippocampus and cerebral cortex AChE and BChE levels. All the data were analyzed by one-way ANOVA, followed

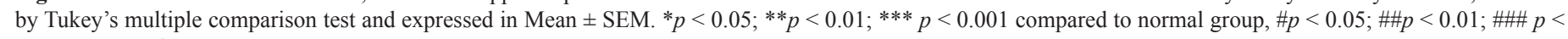
0.001 compared to SCP group.

$<0.001)$ compared to the SCP group, whereas SCP with AT 800 $\mathrm{mg} / \mathrm{kg}$ showed a significant decrease in the MDA level $(p<0.01)$ compared to SCP group. The effect of $A$. tricolor on the MDA level is shown in Figure $4 b$ and Table 4.

\section{Effect of $A$. tricolor extract on reduced GSH}

The SCP group showed a significantly decreased level of GSH $(p<0.001)$ compared to the normal group. Treatment of SCP with the DNPZ group indicated a significant increase in the reduced
GSH level $(p<0.001)$, whereas treatment of SCP with AT $400 \mathrm{mg}$ / $\mathrm{kg}(p<0.01)$ and SCP with AT $800 \mathrm{mg} / \mathrm{kg}(p<0.001)$ showed a significant increase in GSH level. However, no significant change was observed in SCP with AT $200 \mathrm{mg} / \mathrm{kg}$. The effect of $A$. tricolor on a reduced GSH level is shown in Figure $4 \mathrm{c}$ and Table 4.

\section{Effect of A. tricolor extract on reduced SOD}

The SCP group showed a significant decline in the SOD level $(p<0.001)$ compared to the normal group. Treatment of 
Table 4. Effect of A. tricolor on amyloid-beta (1-42), LPO, GSH, and SDO on rat whole brain.

\begin{tabular}{|c|c|c|c|c|}
\hline Treatment groups & Amyloid-beta (1-42) concentration in $\mathrm{pg} / \mathrm{ml}$ & LPO (in nmoles of MDA/mg protein) & GSH (in $\mu$ moles/mg of protein) & SOD (units / mg of protein) \\
\hline Normal & $1.07 \pm 0.049$ & $07.00 \pm 1.186$ & $9.41 \pm 0.657$ & $288.1 \pm 21.99$ \\
\hline SCP & $2.15 \pm 0.155^{* * *}$ & $20.11 \pm 1.341^{* * *}$ & $1.34 \pm 0.166^{* * * *}$ & $107.3 \pm 05.83^{* * * *}$ \\
\hline $\mathrm{SCP}+\mathrm{DNPZ}$ & $1.15 \pm 0.043^{\# \#}$ & $07.83 \pm 1.106^{\# \#}$ & $7.00 \pm 0.423^{\ldots+\ldots \#}$ & $264.7 \pm 28.83^{\# \#}$ \\
\hline $\mathrm{SCP}+\mathrm{AT} 200$ & $2.10 \pm 0.049$ & $17.13 \pm 0.233$ & $2.33 \pm 0.332$ & $131.7 \pm 12.67$ \\
\hline $\mathrm{SCP}+\mathrm{AT} 400$ & $1.63 \pm 0.021^{\# \#}$ & $14.86 \pm 1.398$ & $4.14 \pm 0.300^{\# \#}$ & $185.8 \pm 19.47$ \\
\hline $\mathrm{SCP}+\mathrm{AT} 800$ & $1.39 \pm 0.026^{\# \#}$ & $10.99 \pm 1.070^{\# \#}$ & $5.88 \pm 0.335^{\# \# \#}$ & $212.1 \pm 28.65^{\#}$ \\
\hline
\end{tabular}

Values are expressed in mean \pm SEM: $(n=6)$; Analyzed by one-way ANOVA, followed by Tukey's multiple comparison test.

$* * * p<0.001$ compared to normal group, $\# p<0.05$; \#\#p $<0.01$; \#\# $<0.001$ compared to SCP group.

a) Amyloid beta(1-42) level in brain

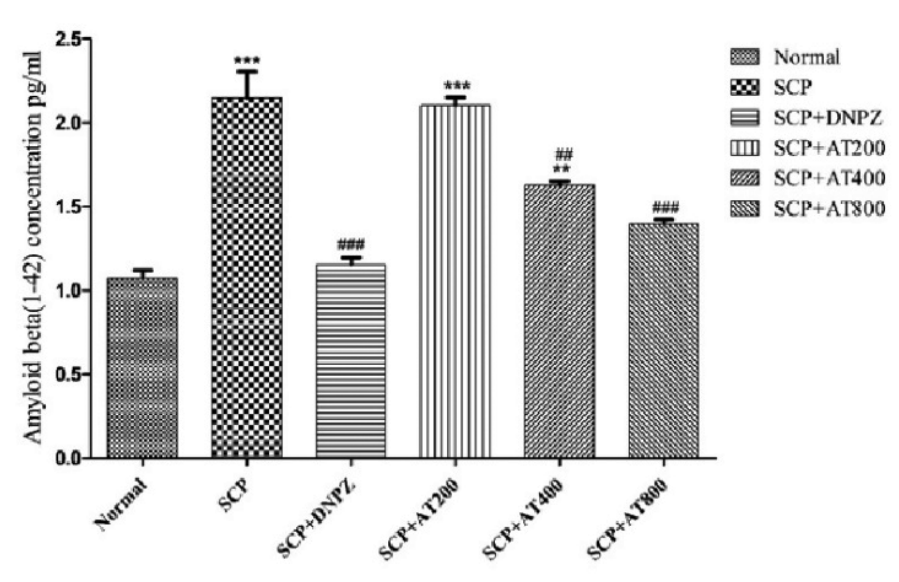

c) GSH level in rat brain

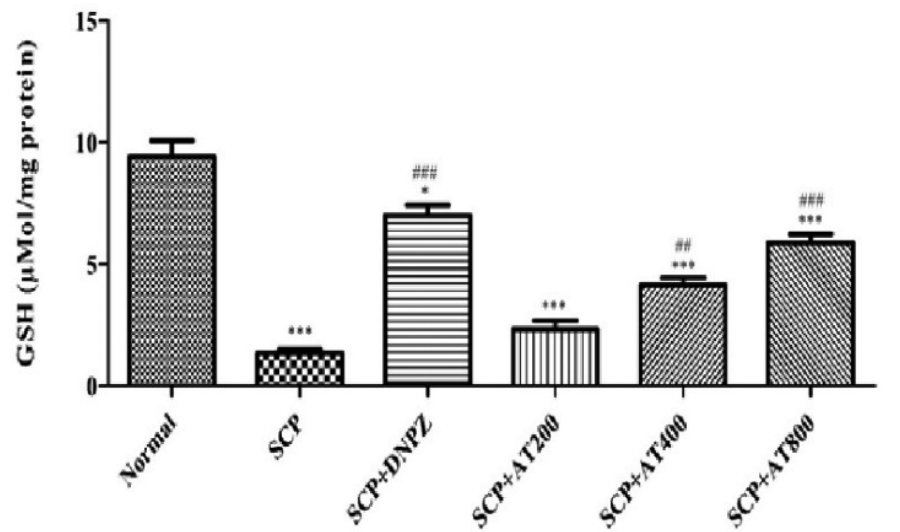

b) MDA level in rat brain

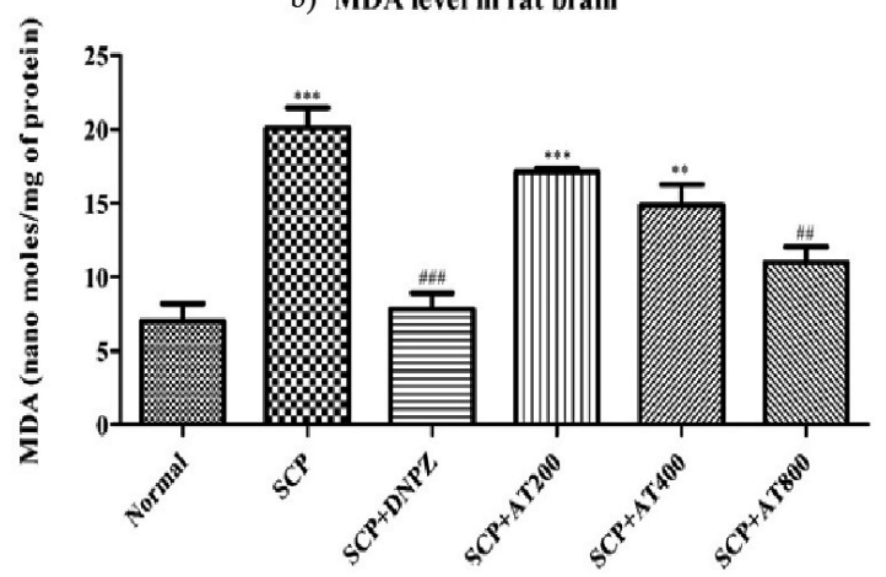

d) SOD level on rat brain

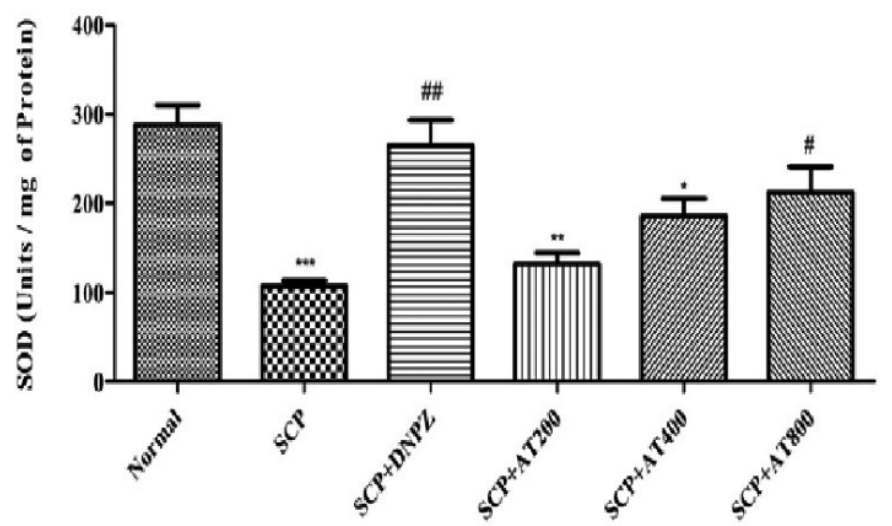

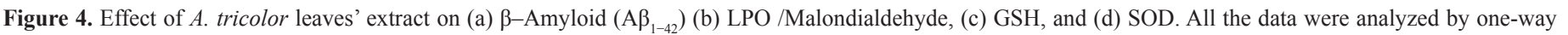

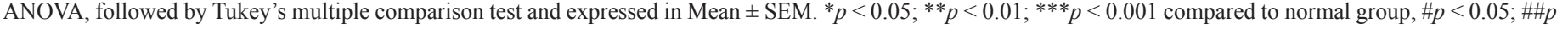
$<0.01$; \#\# $p<0.001$ compared to SCP group.

SCP with DNPZ and SCP with AT $800 \mathrm{mg} / \mathrm{kg}$ group indicated a significant increase in the reduced SOD level $(p<0.01$ and $p$ $<0.05$, respectively) compared to SCP alone. The effect of $A$. tricolor on a reduced SOD level is shown in Figure 4d and Table 4.

\section{DISCUSSION}

Ayurveda is an ancient system of medicine that originated and was practiced in India since ages (Sheeja Malar et al., 2017). It is a holistic system that uses mostly herbal plants, vegetables, and minerals in prescriptions that play a crucial role in the treatment of various diseases because of their antioxidants properties and therapeutic effects. The primary central goal in neuroscience is the advancement of pharmacologically successful medicines which ease neurodegenerative issues. The high event of dementia, in $\mathrm{AD}$, in old individuals gives solid inspiration to look and build up the new substances with the possibility to invert the deficit in 
short and long-term memory. The current pharmacotherapy of AD includes the extreme utilization of conventional AChE inhibitors, i.e. donepezil, rivastigmine, etc., which is apparent to cause a verity of adverse effect and also lose the effect as the disease progresses (Waldemar et al., 2007; Mayo Clinic, 2018). A. tricolor is a leafy vegetable and has a high content of antioxidants and secondary metabolites. One of the studies conducted on A. tricolor L. showed a neuroprotective effect on gene expression of Receptor for advanced glycation endproducts (RAGE) during oxidative stress in SH-SY5Y cells. However, the potential of biochemicals regulated by the bioactive phytoconstituents from $A$. tricolor $\mathrm{L}$. in the management of cognitive impairment has not been elucidated clearly.

SCP-induced memory impairment is one of the best models for assessment of drug candidates for their memoryenhancing potency by utilizing various models such as MWM, EPM, Actophotometer, CPC, and also for determining the level of $\mathrm{ACh}, \mathrm{BCh}, \mathrm{MDA}$, and $\mathrm{GSH}$ in the hippocampus and cerebrum. In the current study, to assess the neuroprotective activity of $A$. tricolor, we administered SCP alone and in combination with 200, 400 , and $800 \mathrm{mg} / \mathrm{kg} /$ day $A$. tricolor extract to the rats and examined their behavior by utilizing MWM, EPM, Actophotometer, and $\mathrm{CPC}$, followed by determining the level of AChE and BChE enzyme activity and reduced antioxidant defence mechanism, i.e. reduced GSH and SOD levels and MDA level in the rat brain. A clinically approved drug "Donepezil" is used as an internal standard at $3 \mathrm{mg} / \mathrm{kg} /$ day dose.

An imbalance in the free radical and Reactive oxygen species (ROS) generation decreases the antioxidant defense mechanism leading to cell damage and inflammation (Manoharan et al., 2016). Furthermore, generation (production) of ROS lead to various unwanted reactions, including DNA damage, lipid abnormalities, and damage to the proteins (Khansari et al., 2009). Researchers demonstrated that plant extracts with higher flavonoid contents usually have the best free radical scavenging property (antioxidant activity). In the current study, the ethanolic extract exhibited strong DPPH scavenging activity and the extract treated in combination with the SCP significantly reversed the oxidative stress mediated by the SCP in rat brain by reducing the MDA level and increasing GSH and SOD levels $(p<0.001)$.

The memory-improving activity of $A$. tricolor against SCP-induced cognitive impairment in rats was examined by utilizing the MWM, EPM, CPC, Actophotometer, and by assessing the biochemical from the cerebrum. The short-term memory was tested utilizing MWM and CPC apparatus. In the current study, animals treated with SCP elevated the brain function by altering the ELT, TL, and locomotion. However, combined therapy of SCP and $A$. tricolor for 14 days showed a dose-dependent decline in the ELT and an increase in the TL and locomotion in rats. Among the selected doses, $800 \mathrm{mg} / \mathrm{kg}$ showed better activity compared to the clinically approved drug. The outcomes of the results propose that the administration of $A$. tricolor changes the neuronal performance of rats from day 7 to 14 and reduced the risk of development of $\mathrm{AD}$ by acting as an antioxidant and altering the disease-associated proteins and pathways. Furthermore, we examined the cholinergic function and beta-amyloid level of the brain to elucidate the memory improvement mechanism of A. tricolor. ACh and $\mathrm{BCh}$ neurotransmitters involved in the memory improvement, the concentration of $\mathrm{ACh}$ is reduced, and $\mathrm{BCh}$ is increased in $\mathrm{AD}$ due to rapid hydrolysis by $\mathrm{AChE}$ and $\mathrm{BChE}$ enzyme activity, respectively (Jung et al., 2009). In the current study, initially, we examined $A$. tricolor on the AChE enzyme and A. tricolor extract showed good inhibitory activity. The in vivo hippocampus and cerebral cortex $\mathrm{AChE}$ and $\mathrm{BChE}$ inhibitory role of A. tricolor was performed at the end of the study, and the resulting outcome showed the dosedependent significant decline in AChE and BChE enzyme activity on the treatment of 200,400 , and $800 \mathrm{mg} / \mathrm{kg}$ of $A$. tricolor extract compared to SCP alone. The results suggest that the administration of 400 and $800 \mathrm{mg} / \mathrm{kg}$ of $A$. tricolor extract could be the potent inhibitory dose compared to Donepezil. Amyloid beta (1-42) level on the whole brain of the rat was examined using a sandwich ELISA kit. Results showed that $A$. tricolor $800 \mathrm{mg} / \mathrm{kg}$ significantly reduced the level of deposition of amyloid-beta in the brain compared to the SCP. Therefore, A. tricolor leaves' ethanolic extract could be the potent treatment regimen against oxidative stress-mediated AD.

\section{CONCLUSION}

In conclusion, the current study describes the molecular mechanism of $A$. tricolor on cognitive improvement via in vitro and in vivo studies. Amaranthus tricolor ameliorates the SCP-induced cognitive dysfunction and oxidative stress by the restoration of the cholinergic function, reducing APP deposition, by inhibiting the LPO, increasing GSH, and SOD function in the brain. The study also demonstrated the improvement of memory by utilizing MWM, EPM, Actophotometer, Cock's pole climbing behavioral models. Therefore, the present study helps the multipronged solutions to tackle AD in the future.

\section{ACKNOWLEDGMENTS}

The authors thank Vital Laboratories Pvt. Ltd, Gujarat, and Apotex pharmaceuticals, Bengaluru, for providing Scopolamine $\mathrm{HBr}$ and Donepezil, respectively, as gift samples. The authors also thank the Principal of KLE College of Pharmacy, KAHER, for providing necessary infrastructure facilities.

\section{CONFLICT OF INTEREST}

The authors declare that there is no conflict of interest regarding the publication of this manuscript.

\section{FUNDING}

None.

\section{REFERENCES}

Al-Dosari MS. The effectiveness of ethanolic extract of Amaranthus tricolor L.: a natural hepatoprotective agent. Am J Chin Med, 2010; 38(06):1051-64.

Ali TB, Schleret TR, Reilly BM, Chen WY, Abagyan R. Adverse effects of cholinesterase inhibitors in dementia, according to the pharmacovigilance databases of the United-States and Canada. PLoS One, 2015; 10(12):1-10.

Amicarelli V, Camaggio G. Amaranthus: a crop to rediscover. In forum ware international: international society of commodity science and technology (IGWT). Vienna, Austria, vol. 2, pp 4-11, 2012.

Amornit W, Santiyanont R. Neuroprotective effect of amaranthus lividus and Amaranthus tricolor and their effects on gene expression of RAGE during oxidative stress in SH-SY5Y cells. Genet Mol Res, 2016; 15:15027562. 
Asaduzzaman M, Uddin MJ, Kader MA, Alam AHMK, Rahman AA, Rashid M, Kato K, Tanaka T, Takeda M, Sadik G. In vitro acetylcholinesterase inhibitory activity and the antioxidant properties of aegle marmelos leaf extract: implications for the treatment of alzheimer's disease. Psychogeriatrics, 2014; 14, 1-10; doi:10.1111/psyg.12031

Bhosale AU, Yegnanarayan, Pophale DP, Zambare RM, Somani SR, Study of central nervous system depressant and behavioral activity of an ethanol extract of achyranthes aspera (Agadha) in different animal models. Int J Appl Basic Med Res, 2011; 1(1):104-8.

Bhuvanendran S, Kumari Y, Othman I, Shaikh MF. Amelioration of cognitive deficit by embelin in a scopolamine-induced alzheimer's disease-like condition in a rat model. Front Pharmacol, 2018; 9(6):1-12.

Blois MS. Antioxidant determinations by the use of a stable free radical. Nature, 1958; 181:1199-200.

Ellman GL, Courtney KD, Andres Jr V, Featherstone RM. A new and rapid colorimetric determination of acetylcholinesterase activity. Biochem Pharmacol, 1961; 7(2):88-95.

Huang HC, Jiang ZF. Accumulated amyloid- $\beta$ peptide and hyperphosphorylated tau protein: relationship and links in Alzheimer's disease. J Alzheimer's Dis, 2009; 16(1):15-27.

Ishola IO, Ikuomola BO, Adeyemi OO. Protective role of spondias mombin leaf and Cola acuminata seed extracts against scopolamine- induced cognitive dysfunction. Alex J Med, 2018; 54(1):27-39.

Jung HA, Min BS, Yokozawa T, Lee JH, Kim YS, Choi JS. Antialzheimer and antioxidant activities of Coptidis Rhizoma alkaloids. Biol Pharm Bull, 2009; 32(8):1433-8.

Kadian R, Parle M. Evaluation of anti-psychotic effect of allium cepa. World J Pharm Pharm Sci, 2014; 3(11):1146-59.

Khansari N, Shakiba Y, Mahmoudi M. Chronic inflammation and oxidative stress as a major cause of age-related diseases and cancer. Recent Pat Inflamm Allergy Drug Discov, 2009; 3(1):73-80.

Manoharan S, Guillemin GJ, Abiramasundari RS, Essa MM, Akbar M, Akbar MD. The role of reactive oxygen species in the pathogenesis of Alzheimer 's disease, parkinson's disease, and huntington's disease: a mini review. Oxid Med Cell Longev, 2016; 2016:1-15.

Mayo Clinic. Alzheimer's: drugs help manage symptoms. Available via https://www.mayoclinic.org/diseasesconditions/ alzheimersdisease/indepth/alzheimers/art-20048103 (Assessed 12 May 2018).

Pattanashatti LA, Taranalli AD, Parvatro V, Malabade R, Kumar D. Pattanashatti LA, Taranalli AD, Parvatro V, Malabade R, Kumar D. Evaluation of neuroprotective effect of quercetin with donepezil in scopolamine-induced amnesia in rats. Indian J Pharmacol, 2017; 49(1):60-4.
Sable KV, Saswade RR. Preliminary phytochemical analysis of Amaranthus spinosus leaves. Int J Life Sciences, 2017; 5(4):742-5.

Shalavadi MH, Chandrashekhar VM, Avinash SP, Sowmya C, Ramkishan A. Neuroprotective activity of stereospermum suaveolens DC against 6-OHDA induced parkinson's disease model. Indian J Pharmacol, 2012; 44(6):737.

Sharma J, Chawla R, Kumar R, Sharma A, Sharma RK, Arora, R. Camellia sinensis as a safe neuroprotective radiation counter measure agent. Int J Pharm Sci Invent, 2013; 2:26-33.

Sheeja Malar D, Beema Shafreen R, Karutha Pandian S, Pandima Devi K. Cholinesterase inhibitory, anti-amyloidogenic and neuroprotective effect of the medicinal plant Grewia tiliaefolia-an in vitro and in silico study. Pharm Biol, 2017; 55(1):381-93.

Uddin MS, Al Mamun A, Hossain MS, Ashaduzzaman M, Noor MA, Hossain MS, Uddin MJ, Sarker J, Asaduzzaman M. Neuroprotective effect of Phyllanthus acidus L. on learning and memory impairment in scopolamine-induced animal model of dementia and oxidative stress: natural wonder for regulating the development and progression of Alzheimer's disease. Adv Alzheimer Dis, 2016; 5(2):53-72.

Uttara B, Singh AV, Zamboni P, Mahajan RT. (2009). Oxidative stress and neurodegenerative diseases: a review of upstream and downstream antioxidant therapeutic options. Curr Neuropharmacol, 7, 65-74. http:// dx.doi.org/10.2174/157015909787602823.

Waldemar G, Dubois B, Emre M, Georges J, Mckeith IG, Rossor M, Scheltens P, Tariska P, Winblad B, EFNS. Recommendations for the diagnosis and management of Alzheimer's disease and other disorders associated with dementia: EFNS guideline. Eur J Neurol, 2007;14:1-26.

Zahra R, Shiva M, Samira A, Mostafa G, Samira R, Mahmoud RK. Inhibitory effect of Thymus vulgaris extract on memory impairment induced by scopolamine in rat. Asian Pac J Trop Biomed. 2015;5(10):806-11.

How to cite this article:

Hupparage VB, Rasal VP, Patil VS, Patil PP, Mulange SG, Malgi AP, Patil SA, Karade AR. Ameliorative effect of Amaranthus tricolor L. leaves on scopolamine-induced cognitive dysfunction and oxidative stress in rats. J Appl Pharm Sci, 2020; 10(10):111-120. 